\title{
Patterns and Trends of Development Communication Studies Conducted by Students of a State University in the Philippines
}

\author{
Avril Adrianne DG Madrid' and Editha G. Cagasan ${ }^{2}$ \\ ${ }^{1}$ SEAMEO Regional Centre for Graduate Study and Research in Agriculture, \\ College, Los Baños, Laguna 4031 Philippines; '2 Department of Development \\ Communication, Visayas State University, Visca, Baybay City, Leyte 6521-A \\ Philippines
}

\section{ABSTRACT}

As part of their academic requirements, graduate and undergraduate development communication (DevCom) students of the Visayas State University (VSU) in the Philippines are required to write a thesis. This study aimed to identify patterns and trends in DevCom research by VSU students. It examined the development context, focus, theoretical bases, methods used and the major findings of their research. A total of 203 studies were content analyzed. Results showed that between 1979 to 1989 , most of the students' research were on agriculture, mass media and health. In the recent years, there has been an accommodation of other development issues including health, environment and information communication technology. Most of the studies, however, focused mainly on two areas of communication research - audience and effects. Although communication books list more than 200 communication theories, only 18 were used in the students' research. Most of the studies used quantitative methods, but an increase in the number of qualitative studies or a combination of the two was noticed in recent years. A good number of the studies tested relationships among variables. The major findings of most of these studies were: (1) information exposure significantly influenced knowledge, attitude and practice; and (2) the socio-demographic variables that most often emerged to have significant relationship with knowledge, attitude and practice were age, sex, educational attainment and income.

Key words: DevCom studies, research agenda, content analysis

\section{INTRODUCTION}

In the Philippines, development communication as a field of study originated from the College of Development Communication (CDC) at the University of the Philippines in Los Baños (UPLB). The College, which began as the Department of Agricultural Information and Communication

Correspondence: Editha G. Cagasan Address: Department of Development Communication, Visayas State University, Visca, Baybay City, Leyte 6521-A Philippines Email: edithcagasan@vsu.edu.ph DOI: $10.32945 /$ atr38212.2016 
(DAIC), offered the first communication course in the country in 1960 under the Bachelor of Science in Agriculture curriculum (College of Development Communication [CDC], 2008). In 1974, the DAIC became the Department of Development Communication (DDC). It was the "first to offer degree programs in development communication in the world" (CDC, 2008). Since then, the department has grown into the CDC, which offers the Bachelor of Science, Master of Science, Master of Professional Studies (via distance mode) and Doctor of Philosophy in Development Communication programs.

The main reason for offering an academic program in development communication is to enhance the general well-being of the Filipino people through the development of manpower that can design communication strategies for effective dissemination and application of relevant knowledge and technology. Decades ago Quebral (1975) asserted that, "in the Philippines, the regional agricultural colleges proposed by the national Educational Task Force might be the proper venue for development communication as a curriculum" (p. 28).

The then Visayas State College of Agriculture (ViSCA), now known as the Visayas State University (VSU) answered the call to build up the development communication curriculum among its academic programs. It started to offer development communication as a field of study in 1977. Development communication was offered first by the Department of Agricultural Development Education (DADE) as a specialization to the Bachelor of Science in Agricultural Development Education (BSADE) program. In 1986 it was offered as a degree program at the Department of Development Communication (DDC). In 1994, DDC offered the Master of Science in Development Communication (MSDC).

In 1979, the Development Communication Section, which later grew into a department, graduated its first batch of students who wrote a thesis as a requirement for graduation. Since then, more than 200 graduate and undergraduate theses have been prepared at the department.

As the department continues to strive to contribute to the body of knowledge in development communication, there is a need to take a retrospective look into its research outputs. The results will be used as guide in formulating DDC's development communication research agenda for the coming decades.

In his article published in the Philippine Journal of Development Communication, Librero (2008) pointed out the need to conduct metaanalysis of research outputs to be able to "formulate a grounded theory of development communication the way it is practiced in the developing world" (p. 197). Kim and Weaver (2002) also stressed the importance of examining and drawing upon research patterns in the past because it would allow us to formulate directions for future communication research.

Meta-research on communication studies conducted in the past (i.e., Fair, 1989; Fair and Shah, 1997; Shah, 2007; Samonte, 1975; Cagasan et al. 2008; Cooper et al. 1994; Riffe and Freitag, 1997; Weaver, 2000; Perloff, 
1976) examined several variables including focus and context of the research, theoretical bases of the studies, methods used in gathering the data, and major research findings.

Guided by the above related studies, this study was conducted to identify patterns and trends in the context, focus, theoretical frameworks, methodologies and major findings of the development communication research conducted by the graduate and undergraduate students at the DDC since 1979. Anchored on the systems theory, the main assumption of this research is that development communication research in VSU-DDC is influenced by changes in the dominant paradigms in development communication scholarship in the Philippines and the world.

\section{METHODOLOGY}

To answer the research objectives, this study used meta-research because it permits the systematic examination of trends in a group of completed research studies on a common subject matter.

Data for this study were gathered by examining all available undergraduate and graduate theses prepared at the DDC from 1979 to 2008. To facilitate analysis of the patterns and trends of the development communication studies, the period covered in this research was divided into three decades, i.e. first decade (1979 to 1989), second decade (1990 to 1999) and third decade (2000 to 2008).

Each study was coded for the year it was conducted, context, focus, theoretical frameworks used, methodologies employed and the major findings. Information from the studies were synthesized to arrive at the most commonly occurring research results and to propose a research agenda for the Department of Development Communication in VSU.

To facilitate understanding, the major concepts used in this study are operationally defined below.

Context refers to the general topic where the study's subject matter is situated. These included agriculture, health, education, environment, religion, mass media, gender and ICT. Those that could not be classified under these categories were put under 'others.'

Research focus refers to the focal point of the study which was comprised of four general concerns: people (people involved in the communication process), effects (media effects), policy (factors and processes that play a role in the development or improvement of communication policies) and normative research (finding better ways of communicating).

Theoretical base refers to the communication, social science or development theories that framed the study. The studies were examined for any mention of specific theories or explicitly stated hypotheses derived from a named theory. All the theories that were used in each study were listed and the main theoretical underpinning of the study was identified. These include social cognitive theory, theory of planned behavior, 
constructivism, and others.

Research approach refers to the approach or method used in the study. Methods were categorized as quantitative, qualitative or a combination of both. Quantitative approaches included studies that reported data in means and percentages as well as statistics that allowed generalization to the population as a whole. Qualitative approaches included studies that used themes and narrative descriptions to report their data. Studies that used a combination of quantitative and qualitative approaches were categorized as such.

Methods refer to the procedures used to gather data. Methods used in each study were listed. These included survey, focus group discussion, content analysis, literature review, in-depth interviews, secondary data analysis, case studies, ethnography, and observation. Those that could not be classified under these categories were put under 'others.'

Findings refer to the major results of the studies.

The coders read each study thoroughly and coded them for the above mentioned attributes. As the analysis proceeded, the coding scheme of the categories used for this study was generated inductively.

To check for intercoder reliability using Cohen's kappa, 23 (10\%) of the total number of development communication studies were randomly selected. Two coders, a trained research assistant and one of the researchers, analyzed the items according to the coding scheme. The studies used in the intercoder reliability, which was a subset of the study data, were included in the actual analysis. Cohen's kappa was chosen as the index for reliability as it is a widely-accepted measure of choice (Dewey, 1983). According to Lombard, Snyder-Duch and Bracken (2002) coefficients of .90 or greater are nearly always acceptable, .80 or greater is acceptable in most situations, and .70 may be appropriate in some exploratory studies for some indices.

Results of the intercoder reliability for the overall coding scheme was .964 using Cohen's kappa coefficient. This means that there was high agreement between the two coders, showing good operationalization and categorization of the variables being studied.

\section{RESULTS AND DISCUSSION}

\section{Profile of the Development Communication Studies}

A little more than a tenth $(11.8 \%)$ of the 203 thesis manuscripts included in this study were written from 1979-1989. Almost a fourth $(22.7 \%)$ were written from 1990 to 1999 , and the bulk (65.5\%) from 2000 to 2008 .

Almost all of the studies (97\%) were written by undergraduate students and only very few (3\%) were written by graduate students. A little more than a tenth $(11.8 \%)$ were written by students who took general development communication, nearly half (43.8\%) were prepared by 
community broadcasting majors, a little more than a third (35\%) were written by development journalism majors, and few (6.4\%) were prepared by educational communication technology majors. Of the 203 studies, a little more than three-fifths (65.5\%) were theses, the rest (34.5\%) were case studies. At DDC, undergraduate students are given the option to write a thesis or do an internship or practicum. Students who opt for internship are still required to write a case study.

A little more than half (53.9\%) of the research studies were done in rural areas while the rest were done in urban $(28 \%)$ areas or a combination (12.4\%) of both. A very small percentage (5.7\%) was content analyses that were done in university libraries. Almost half of the studies were conducted in Leyte province (52.2\%) and the rest in Cebu (10.5\%), Bohol (6.9\%), Southern Leyte (3.1\%) and Eastern Samar (1.1\%). These show that the studies focused on the impact zone of Visayas State University - the province of Leyte and its neighboring provinces such as Eastern Samar and Bohol. Almost a third (29.1\%) of the studies conducted in Leyte were done in Baybay. This is largely due to the composition of the development communication students. Majority of them were residents of Baybay and towns and cities in Leyte, and they conducted their studies in their hometowns or in Baybay.

\section{Research Context}

Table 1 shows that in the first decade of DDC's existence, all of the development communication studies conducted by VSU students were situated in only two contexts: agriculture $(83.3 \%)$ and the mass media $(16.7 \%)$. This narrow focus on agriculture in the early years of communication research at the department can be explained by its history. Before 1984, the department was just a unit in the Department of Agricultural Development Education (DADE). The unit offered development communication as a specialization in the BS in Agricultural Development Education (BSADE) curriculum. When the Visayas State College of Agriculture (ViSCA) became a university, the department was situated in the College of Agriculture. One of DDC's missions in the university is to disseminate information about agricultural technologies to achieve development in the countryside.

During the second decade (1990 to 1999), there was a noticeable shift in the context of most of the studies from agriculture $(23.9 \%)$ to mass media (65.2\%). Studies categorized under the mass media were those that concentrated on the listenership of radio, readership of newspapers and viewership of television as well as the content of these media. The high percentage of research under the mass media context can be explained by the increase in the number of students who opted for internships in media outfits (i.e., radio and TV stations and newspaper agencies). While doing their internship activities, they also conducted case studies about newspaper readership, and listenership or viewership of the programs 
aired over the radio or TV stations where they had their internship. There were also studies done in other contexts such as environment $(4.3 \%)$, health $(2.2 \%)$, gender $(2.2 \%)$ and information communication technologies $(2.2 \%)$. This means that during the second decade, DevCom students already started to consider other development issues as the subject of their studies.

Table 1. Research contexts of development communication studies (1979-2008)

\begin{tabular}{lccc}
\hline \multicolumn{1}{c}{ Research } & $\begin{array}{c}\text { First Decade }(1979- \\
1989)\end{array}$ & $\begin{array}{c}\text { Second Decade } \\
(1990-1999)\end{array}$ & $\begin{array}{c}\text { Third Decade } \\
(2000-2008) \\
(\%)\end{array}$ \\
& $\mathrm{N}=24$ & $\mathrm{~N}=46$ & $\mathrm{~N}=133$ \\
\hline Agriculture & 83.3 & 23.9 & 15.0 \\
Mass Media & 16.7 & 65.2 & 33.8 \\
Health & 0.0 & 2.2 & 22.6 \\
Education & 0.0 & 0 & 6.8 \\
Environment & 0.0 & 4.3 & 13.5 \\
Gender & 0.0 & 2.2 & 2.3 \\
ICT & 0.0 & 2.2 & 3.8 \\
Others & 0.0 & 0.0 & 2.3 \\
\hline
\end{tabular}

In the most recent years, the DDC research contexts have already accommodated a variety of development issues. Mass media (33.8\%) still topped the list although studies on health communication $(21.8 \%)$ are steadily on the rise. Agriculture (15\%) and the environment (13.5\%) are still areas of communication research interest while there is an increasing trend in studies that take education (6.8\%) as the context. This is mainly because in 2004, DDC implemented educational communication technology as the third and newest specialization or major in the BSDC curriculum. Information communication technologies (3.8), gender $(2.3 \%)$ and other $(2.3 \%)$ contexts such as work safety measures, tenure security and public figure credibility were also being studied.

It is interesting to note the steady diversification of contexts in which development communication research has been done in VSU. This implies that students have recognized that there are more facets to development aside from agriculture and economic improvement. This finding corroborates those of Cagasan et al. (2008) who found a similar trend among the studies done at the College of Development Communication at UPLB. The contexts taken into consideration in development communication can be seen to be influenced by the United Nations' publication of the Millennium Development Goals (MDG) in 2000. In defining the development problem to be addressed, thesis advisers usually remind students to use the MDGs to focus their research on. 


\section{Research Focus}

The studies at DDC focused on four areas of communication research (Table 2).

In the first decade, studies that focused on the people (58.3\%) involved in the communication process dominated. Effects research accounted for almost a third (29.2\%) of the studies. A little more than a tenth $(12.5 \%)$ were studies that were meant for policy-making in the many media outfits.

In the second decade the focus shifted to policy (56.5\%), followed by people $(32.6 \%)$. Interestingly, normative research $(8.7 \%)$ meant to improve the content and process of the various media first appeared. In this decade, there were very few effects $(2.2 \%)$ studies.

The same trend was observed in the studies conducted in most recent years; research on people (53.4\%) or audience research was dominant. Studies on people were those whose focal points were measuring the perceptions, knowledge, attitude, practice, and beliefs of the audiences of a wide variety of communication media including TV, print, radio and community media such as folk songs and theater presentations. Studies centered on policy (26.3\%), effects $(12.8 \%)$ and normative $(7.5 \%)$ recommendations followed.

Table 2. Research foci of the development communication studies conducted by VSU students (1979-2008)

\begin{tabular}{lccc}
\hline Research & First Decade & Second Decade & Third Decade \\
Focus & $(1979-1989)(\%)$ & $(1990-1999)(\%)$ & $(2000-2008)(\%)$ \\
& $\mathrm{N}=24$ & $\mathrm{~N}=46$ & $\mathrm{~N}=133$ \\
\hline People & 58.3 & 32.6 & 53.4 \\
Effects & 29.2 & 2.2 & 12.8 \\
Policy & 12.5 & 56.5 & 26.3 \\
Normative & 0.0 & 8.7 & 7.5 \\
\hline
\end{tabular}

\section{Theoretical Bases of the Development Communication Studies}

None of the studies in the first and second decades employed a theoretical framework. The analysis showed that it was only in 2003 when a theoretical framework became part of the student thesis. Case studies conducted by students who did internships in communication outfits in Regions 7 and 8 and in Manila were not required to present a theoretical framework.

Of the 133 studies conducted in 2003 onwards, $92 \quad(69.2 \%)$ were theses and 41 (30.8\%) were case studies. Of the theses, a little less than a third (32.6\%) did not report using a theoretical framework while the rest $(67.4 \%)$ did. Almost all of the theses concentrated on theory-testing; only four studies (3\%) attempted to build theories through the application of the principles of grounded theory. 
Scholars like Anderson (1996) who surveyed communication textbooks found 249 distinct communication theories. Of the many available theories in communication, only 18 were used by development communication studies conducted by VSU students. Of the 18 theories, only eight were used more than once.

Social cognitive $(22.2 \%)$ and social learning theories $(15.9 \%)$ were most often used in the studies (Table 3). These were followed by constructivism (14.3\%), theory of planned behavior (7.9\%), uses and gratifications approach (6.3\%), convergence model $(4.8 \%)$, prospect theory ( $4.8 \%)$, and systems theory (3.2\%). Only one study each reported using other theories which include the following: social construction of reality, social amplification of risk framework, agenda-setting, selective exposure, dual-coding, cognitive response theory, perception, issueattention cycle, cognitive theory of multimedia learning, collaborative learning, communicative action, health belief model and Berlo's SMCRE model of communication.

The studies which were anchored on the social cognitive and social learning theories were quantitative studies which focused on the influence of information exposure on the knowledge, attitudes, and practices (KAP) of respondents in relation to the use of some recommended technologies, products, or ideas. The studies which used the theory of planned behavior were also quantitative studies which examined the influence of people's socio-phychological factors (i.e., beliefs, attitudes, perceived behavioral control and subjective norms) on their intentions and actual behavior. On the other hand, studies aligned with constructivism were qualitative studies which aimed to understand the outcomes of communication processes as experienced by people in certain contexts.

Table 3. Theories applied in development communication studies (2003-2008)

\begin{tabular}{lcccccccr}
\hline \multirow{1}{*}{ Theory } & \multicolumn{8}{c}{ Number* } \\
\cline { 2 - 8 } & 2003 & 2004 & 2005 & 2006 & 2007 & 2008 & $\begin{array}{c}\text { Total } \\
\text { (n=62) }\end{array}$ & $\%$ \\
\hline Social Cognitive Theory & 2 & 4 & 2 & -- & 3 & 3 & 14 & 22.6 \\
Social Learning Theory & -- & 1 & 4 & -- & 2 & 3 & 10 & 16.1 \\
Constructivism & -- & -- & 2 & 1 & 2 & 4 & 9 & 14.5 \\
Theory of Planned Behavior & -- & -- & 1 & 1 & -- & 3 & 5 & 8.1 \\
Uses and Gratifications & -- & -- & -- & 1 & -- & 2 & 3 & 4.8 \\
Convergence & -- & -- & -- & 1 & 1 & 1 & 3 & 4.8 \\
Prospect Theory & -- & -- & -- & 2 & 1 & -- & 3 & 4.8 \\
Systems Theory & -- & -- & 2 & -- & -- & -- & 2 & 3.2 \\
Others* & 1 & 0 & 2 & 2 & 7 & 1 & 13 & 21.0 \\
\hline
\end{tabular}

*Social Construction of Reality, Social Amplification of Risk Framework, Agenda-setting, Selective Exposure, Dual-Coding, Cognitive Response Theory, Perception, Issue-Attention Cycle, Cognitive Theory of Multimedia Learning, Collaborative Learning, Communicative Action, Health Belief Model and Berlo's SMCRE Model of Communication 
Research Methods Used

In the first decade, majority of the studies employed quantitative approach (83.3\%), although a few (16.7\%) used qualitative approaches to describe various media outfits. None of the studies used a combination of quantitative and qualitative approaches (Table 4).

In the second decade, quantitative (47.8\%) approaches still topped the list although an increasing number of studies have started to use combined quantitative and qualitative (28.3\%) methods. In this decade, the use of qualitative approaches (23.9\%) also increased.

The primary method being used in development communication studies was the survey (77\%). Almost a tenth used in-depth interviews $(8.9 \%)$ while the rest used content analyses (6.3\%), experiments $(5.2 \%)$, focus group discussions (1.6\%) and ethnography (1\%). Of those studies that employed at least two data-gathering methods, focus group discussions $(40.3 \%)$ were most often used followed by ethnography $(24.2 \%)$, in-depth interviews $(16.1 \%)$, content analyses $(11.3 \%)$ and experiments $(7.9 \%)$. Of those studies that employed at least three datagathering methods, ethnography (61.1\%) was most often used followed by observation (25\%), in-depth interviews (5.6\%), focus group discussions $(5.6 \%)$ and content analysis $(2.8 \%)$. The nine studies that used four methods employed ethnography (56\%), and observation (44\%) as their fourth method.

In the last decade, the use of quantitative methods surged, being applied by almost three-fourths (70.7\%) of all studies. A combination of quantitative and qualitative $(16.5 \%)$ methods followed. A drop from the second decade was seen in the use of qualitative approaches $(12.8 \%)$.

The studies used an average of two methods $(\mathrm{SD}=0.89)$ to gather data. Almost half (44\%) used only one method while almost a third used two (32.6\%). The rest used three (18.7\%) and very few used four $(4.7 \%)$ methods in gathering data.

Table 4. Research methods used by development communication studies

\begin{tabular}{lccc}
\hline \multicolumn{1}{c}{ Methods used } & $\begin{array}{c}\text { First Decade } \\
\left(\begin{array}{c}1979-1989)(\%) \\
\mathrm{n}=24\end{array}\right.\end{array}$ & $\begin{array}{c}\text { Second Decade } \\
(1990-1999)(\%), \\
\mathrm{n}=46\end{array}$ & $\begin{array}{c}\text { Third Decade } \\
(2000-2008)(\%), \\
\mathrm{n}=133\end{array}$ \\
\hline Research Approach & & & \\
Quantitative & 83.3 & 47.8 & 70.7 \\
Quantitative + Qualitative & 0.0 & 28.3 & 16.5 \\
Qualitative & 16.7 & 23.9 & 12.8 \\
& & & \\
Data Gathering Methods & & & \\
Survey & 54.2 & 82.6 & 79.5 \\
Experiments & 25.0 & 0.0 & 3.0 \\
In-depth Interviews & 16.7 & 10.9 & 7.6 \\
Focus Group Discussions & 0.0 & 0.0 & 2.3 \\
Content Analysis & 4.2 & 6.5 & 6.1 \\
Ethnography & 0.0 & 0.0 & 1.5 \\
\hline
\end{tabular}


Major Findings the VSU DevCom Studies

Of the 203 development communication studies, more than half (65.5) were theses. Of these theses, almost half $(49.6 \%)$ did not test for any relationship between the independent and dependent variables. The remaining (32.5\%) studies tested for relationships.

This study did not attempt to synthesize statistical results of the studies being analyzed to come up with effect sizes and similar attributes. This is because there was a large variation in the sample sizes and sampling methods used, the statistical tests applied on the data and the value for the probability of error employed. What was done instead was just to determine what variables had significant relationships. Moreover, studies that did not test for relationships were not included in this section.

Results (Table 5) showed that most of the studies which tested relationships among variables found that:

1. Information exposure significantly influenced the respondents' knowledge, perception, attitudes, behavioral intention and practice;

2. Information exposure was associated with the respondents' educational attainment, age, and information-seeking behavior;

3. The socio-demographic variables that most often emerged to have significant relationship with the respondents' knowledge, perception, attitude, behavioral intention and practice were age, sex, educational attainment, income and membership in organization

These results support the findings of earlier communication researchers (Bynum, et al. 2011; Heong, et al. 2008; Huan, et al. 2008; Tanner, Duhe, Evans and Condrasky, 2008) that information exposure is indeed needed to effect behavioral changes among project clients or beneficiaries. These results also suggest that in designing projects that intend to change people's behavior, the socio-demographic variables that may be given attention include age, sex, educational attainment, income and membership in organization as these are the ones that are significantly associated with people's information exposure, knowledge, attitudes and practices. 
Table 5. Major findings of the development communication studies which tested relationships among variables

\begin{tabular}{lccccc}
\hline $\begin{array}{l}\text { Independent Variables } \\
\text { Tested in DevCom } \\
\text { Studies }\end{array}$ & \multicolumn{1}{c}{ Dependent Variables Tested in DevCom Studies } \\
\hline $\begin{array}{l}\text { Socio-demographic } \\
\text { characteristics }\end{array}$ & Knowledge & Perception & Attitude & $\begin{array}{c}\text { Behavioral } \\
\text { Intention }\end{array}$ & $\begin{array}{c}\text { Behavior/ } \\
\text { Practice } \\
\text { Sex }\end{array}$ \\
Education & $\checkmark$ & $\checkmark$ & $\checkmark$ & $\checkmark$ & $\checkmark$ \\
$\quad$ Income & $\checkmark$ & $\checkmark$ & $\checkmark$ & $\checkmark$ & $\checkmark$ \\
$\quad$ Organizational & $\checkmark$ & $\checkmark$ & $\checkmark$ & $\checkmark$ & $\checkmark$ \\
$\quad$ Membership & $\checkmark$ & $\checkmark$ & $\checkmark$ & n/a & $\checkmark$ \\
Information Exposure & $\checkmark$ & $\checkmark$ & $\checkmark$ & n/a & $\checkmark$ \\
Knowledge & -- & $\checkmark$ & $\checkmark$ & $\checkmark$ & $\checkmark$ \\
Attitude & n/a & n/a & -- & $\checkmark$ & n/a \\
\hline
\end{tabular}

\section{IMPLICATIONS AND RECOMMENDATIONS}

This study attempted to reveal trends in how development communication research has been done by students in the Department of Development Communication (DDC) for the past three decades in the hope of stimulating thought toward DDC research agenda in the decades to come.

Findings of this study gave rise to implications in the development communication research practice of students at DDC. In this section we recommend new considerations in context, focus, theory and approaches for future development communication research.

In terms of context, most of the studies focused on a narrow view of development problems related to agriculture. Since most development problems are often multi-faceted, we recommend the inclusion of a wide variety of contexts in a single study. An example would be combining gender and environment, or education and health, or even information communication technologies and agriculture. Although there have already been a few studies at DDC that were anchored on one or more contexts, there is a need to improve on this. Furthermore, media studies should not stop at understanding the effect of media but should also examine how the audience of the media interpret media content and how the mechanism for feedback is negotiated between the source and the receiver.

When it comes to the research focus of the studies at DDC, audience and effects research have been well-studied. A high import has been placed on understanding the people involved in the communication process. In addition, studies on the mass media emphasized mostly on the effects of media on people's knowledge, attitude and behavior. There is, however, a call for getting a better understanding not only of the components of the communication but also of the process itself. In other words, we not only need to ask what, where and who; we also need to ask why and how. 
There are also very few normative studies that recognize the need to improve the content and process of communication. Future studies can be geared toward addressing these two concerns.

The theories used in the studies can be grouped into only three theoretical classifications following Miller's (2002) categorization. These are theories of message processing, media processing and effects, and message production. In terms of theoretical perspectives, all the theories came out of the post-positivist roots. In essence, the studies were applying theories from a narrow selection. We therefore recommend the utilization of theories that have been seldom or never used in previous research at DDC. For example, theories coming from the interpretive and critical perspectives can be applied in future studies. Moreover, there are a variety of theories of discourse and interaction, organizational and small group communication, media and society and culture and communication that also require empirical testing and theoretical articulation and development.

The restricted use of communication theories to guide the studies at DDC may be explained by the lack of a course that deals specifically with communication theory. In the present curriculum, communication theories are integrated into core and major courses as well as in the class on Research Planning and Manuscript Preparation. This concern is now addressed with the institutionalization of a communication theory course in the new BSDC curriculum in VSU.

Finally, we recommend that the research approaches that have largely been quantitative also accommodate the qualitative approach and the combination of both. Although some studies have already made strides in the qualitative direction, more would be necessary. Majority of the studies used only one method to gather the data although there have been strides into using multiple methods. Employing more than one method of data gathering should be encouraged for a study to obtain a multi-faceted picture of the problem. In addition, there was a very high concentration on the survey as a data gathering method in the studies examined. This implies a reliance on a technique that allows for only a one-time, snapshot of the research problem being examined. This results in a fragmented understanding of the communication process. To acquire a comprehensive picture, we recommend that a quantitative data gathering method be complemented by a qualitative method. Doing so will help articulate not just the components of the communication but the process of communication itself.

Considering all these, we are proposing the following agenda for development communication research among students and faculty of the Department of Development Communication in VSU:

- Research problems should now concentrate not only on agriculture but also on other development issues. The Sustainable Development Goals (SDGs), previously called as the Millennium Development Goals (MDGs), can be a useful basis in identifying research context. 
Among the concerns of the SDGs are health, gender and empowerment, education, environment, peace and governance.

- Instead of focusing on specific elements of the communication process (i.e., source, message, channel, receiver and effects), which have already been done in many development communication studies in DDC, DevCom studies may now start to focus on studying communication processes in different development contexts. For instance, student researchers can start documenting development communication practices or projects that work in different development contexts in the region or in the country. This calls for the accommodation of other research paradigms (i.e., interpretive, critical and even cultural paradigms) and traditions of communication research (i.e., case study, phenomenology, ethnography, etc.), as well as the use of mixed research methods (quantitative and qualitative methods).

- Studies that intend to test theories should now start considering newer and less-studied theories of communication and development. Also, research emphasis may not only be on theory testing but also on theory building.

\section{REFERENCES}

ANDERSON, J. A. 1996. Communication theory: Epistemological foundations. New York: Guilford.

BYNUM, S. A. , MALO, T.L., LEE, JI-HYUN, GUILIANO, A.R., and VADAPARAMPIL, S.T. 2011. HPV vaccine information-seeking behaviors among US physicians: Government, media, or colleagues? Vaccine, 29, 5090-5093.

CAGASAN, E.G. et al. 2008. Constructs of "development" among CDC faculty and in student research studies. Philippine Journal of Development Communication, 1(1), 37-74.

COLLEGE OF DEVELOPMENT COMMUNICATION (CDC). (2008). About us. Accessed September 2, 2008, from College of Development Communication, UPLB: www.devcom.edu.ph/ver2 /index.php?option

COOPER, R., POTTER, W. and DUPAGNE, M. 1994. A status report on methods used in mass communication research. Journalism Educator, 48, 54-61.

DEWEY, M. E. 1983. Coefficients of agreement. British Journal of Psychiatry, 143, 487-489.

FAIR, J. E. 1988. A meta-research of mass media effects on audiences in developing countries from 1958 through 1986. (Doctoral dissertation, Indiana University, 1988).

FAIR, J. E. and SHAH, H. 199. Continuities and discontinuities in communication and development research since 1958. Journal of International Communication , 4(2), 3-23. 
HEONG, K.L., ESCALADA, M.M., HUAN, N.H., KY BA, V.H., QUYN, P.V. THIET, L.V., and CHIEN, H.V. 2008. Entertainment- education and rice pest management: A radio soap opera in Vietnam. Crop Protection, 27, 1392-1397.

HUAN, N. H., CHIEN, H. V., QUYNH, P. V., TAN, P. S., DU, P. V., ESCALADA, M. M. and HEONG, K. L. 2008. Motivating rice farmers in the Mekong Delta to modify pest management and related practices through mass media. International Journal of Pest Management, 54(4), 339 - 346.

JAMIAS, J.J. 1975. The philosophy of development communication. In Juan F. Jamias (Ed.) Readings in development communication. College, Laguna: UPLB College of Agriculture.

KIM, S. T. and WEAVER, D. 2002. Communication research about the internet: A thematic meta-analysis. New Media Society, 4(4), 518-538.

KOLBE, R. H. and BURNETT, M. S. 1991. Content-analysis research: An examination of applications with directives for improving research reliability and objectivity.Journal of Consumer Research, 18, 243-250.

LIBRERO, F. 2004. Development communication research in the Southeast Asian Region: State of the art. Singapore: AMIC.

LIBRERO, F. 2008. Quo vadis development communication? Thoughts on the practice of Devcom in a knowledge society. The Philippine Journal of Development Communication, 1(1), 186197.

LOMBARD, M., SNYDER-DUCH, J., and BRACKEN, C. C. 2002. Content analysis in mass communication: Assessment and reporting of intercoder reliability. Human Communication Research, 28, 587-604.

MILlER, K. 2002. Communication theories: Perspectives, prospects and contexts. Boston: McGraw Hill.

QUEBRAL, N.C. 1975. The making of a development communicator. In J.F. Jamias (Ed.). Readings in Development Communication. Department of Development Communication, UPLB: UPLB.

PERLOFF, R. 1976. Journalism research: A twenty-year perspective. Journalism Quarterly, 53, 123-126.

SAMONTE, V.P. 1975. Development communication research at Los Baños. In J.F. Jamias (Ed.). Readings in Development Communication. Department of Development Communication, UPLB.

RIFFE, D. \& FREITAG, A. (1997). A content analysis of content analyses: Twenty-five years of Journalism Quarterly. Journalism and Mass Communication Quarterly 74(3), 515-524.

SHAH, H. 2007, May. Meta-research of development communication studies, 1997-2005: Patterns and trends since 1958. Paper presented at the annual meeting of the International Communication Association.

TANNER, A., DUHE, S., EVANS, A. AND CONDRASKY, M. 2008. Using studentproduced media to promote healthy eating: A pilot study on the effects of a media and nutrition intervention. Science Communication, 30 (1), 108-125.

WEAVER, D. H. 2000, July. Mass communication research at the end of the 20th century: Looking back and ahead. Paper presented at the International Conference of Schools of Journalism and Communication. 